\title{
Job-Related Circular Mobility and the Quality of Intimate Relationships*
}

\author{
Michael Feldhaus, Monika Schlegel
}

\begin{abstract}
This paper addresses the influence of different types of spatial mobility on relationship quality. Although some studies have been carried out on this question, the existing empirical results remain contradictory. The paper tries to overcome some of these limitations by analysing to what extent mobility demands show direct as well as indirect effects. Spatial mobility could have impacts on crucial aspects of relationship dynamics, which are theoretically and empirically identified as significant for relationship satisfaction. The mediating variables used therefore include relatedness, autonomy, conflict and the perceived fairness with regard to the division of labour. The data support the stress hypothesis which assumes that job-related mobility has a negative effect on the relationship quality, but only for women and mothers. There are actually positive effects for men. In terms of indirect effects, the results show that spatial mobility does neither reduce relatedness in relationships nor increase conflict behaviour significantly. In fact, the opposite effect seems to come to play: There is empirical evidence, especially for women, that more demanding mobility increases the feeling of autonomy within a relationship. It also increases relatedness and reduces perceived conflicts, this in turn having a positive effect on relationship quality.
\end{abstract}

Keywords: Commuting behaviour - Job-related mobility · Relationship satisfaction · Relationship dynamics

The authors would like to thank the reviewers and the editor Eric Widmer for their very useful and valuable advice. 


\section{Introduction}

With regard to daily commuting in the context of a relationship, previous research - particularly from the microeconomic framework - concentrates on analysing the question of why people commute (instead of migrating), what is the rationale behind this and what effects are associated with commuting behaviour. For modelling this question, specific benefits and costs from the current situation as well as anticipated changes are considered and tested against empirical data. Focusing on (expected) benefits and costs, many of these studies focus on indicators such as job-related reasons (e.g. income, status, job search, job stimulation or relations with colleagues), place utilities, bargaining processes, the influence of social networks (e.g. Ommeren 1998; Kalter 1994, 1997; Kaufmann/Widmer 2006; Kley 2010; Abraham/Schönholzer 2009; Abraham et al. 2010). But as Stutzer and Frey (2008) emphasize, commuting cannot be fully understood within the traditional economic framework. Particularly with regard to intimate relationships, other relationship dynamics (such as quality, conflicts, intimacy, sexual satisfaction, intentions regarding family formation, entry into cohabitation or marriage, etc.) are important but are too frequently ignored in the field (Abraham/Schönholzer 2009).

Looking at research linking commuting and relationship satisfaction, empirical findings have been generated more often within a stress-theoretical approach (Koslowsky et al. 1995; Schneider et al. 2002a/b) or in the context of the "Job Mobility and Family Life" project (Limmer/Schneider 2008; Schneider/Meil 2008; Schneider) Collet 2010). Although some analyses have been carried out on this question, empirical results remain unclear and contradictory findings have been ascertained: Some studies find a significant relationship between certain types of mobility and relationship quality (e.g. Rüger/Limmer 2010; Reuschke 2010), while others do not (e.g. Viry et al. 2010). It seems more likely that theoretical and empirical work suggests that job-related circular mobility can be both helpful towards and detrimental to relationship satisfaction.

This has encouraged theoretical speculation that, in most cases, the impact exerted by commuting is probably more indirect than direct via relationship dynamics (such as relatedness, intimacy, conflicts, autonomy, etc.) or other variables such as gender, parenthood, etc. (Schneider et al. 2002a/b; Biehl et al. 2005; Schneider 2005; Viry et al. 2010; Meil 2010a; Hofmeister/Schneider 2010). On this crucial point, no data have been available for testing both the direct and indirect effects of relationship dynamics and job-related circular mobility on the relationship quality simultaneously. New data from the German Family Panel (Huinink et al. 2011) now enable us to overcome some of these limitations. Here we concentrate on commuting behaviour using the examples of daily commuters (long-distance commuter, medium-distance commuter and short-distance commuter) and varimobiles (individuals who spent more than 60 nights away from home for work-related reasons during the last 12 months). These categories are well introduced through previous research in the literature on commuting (Schneider et al. 2002a/b; Schneider/Meil 2008; Rüger et al. 2011). 
Our analysis begins with a brief review of previous findings regarding the impacts of spatial mobility on relationship quality, followed by a theoretical approach to the stress and stimulation mechanisms which might accompany spatial mobility. The ensuing empirical section starts with a cross-sectional analysis to test the direct effects of spatial mobility by distinguishing between different types of daily commuting. Then indirect effects are tested by using mediating variables such as relatedness, autonomy, conflict and the perceived fairness with regard to the division of labour. This paper provides empirical support for unravelling the complex connections between commuting behaviour and intimate relationships, particularly in regard to mediating variables, and thus enriches the ongoing theoretical discussion in a new and valuable way.

\section{Research on spatial mobility and the quality of intimate relationships}

The impact of spatial mobility on relationship quality has been analysed quite often in the context of stress-theoretical approaches (Koslowsky et al. 1995; Limmer 2005). Especially the early study of Schneider et al. (2002a/b) was the first to focus on job-related mobility, and its relation to different domains of the life course such as intimate relationships, family or single life in Germany. This study distinguished between three important types of commuting or job-related mobility. Long-distance commuters travel at least one hour to work. Shuttlers maintain a second home near their workplace and commute back to their place of residence at weekends. Varimobiles are recurrently but irregularly absent from home due to their jobs. Other representative studies followed this differentiation of mobility types (Rüger et al. 2011).

Taken together, the findings regarding the impact of mobility on intimate relationships, family life or individual well-being are rather ambiguous. Schneider et al. $(2002 a / b)$ found that 75 percent of mobile people reported that mobility exerted a negative impact on their relationships. They mentioned conjugal conflicts and closeness-distance problems as well as conflicts in regard to sexual satisfaction or to the division of domestic chores (see also Bieh/ et al. 2005). Particularly mobile women receive little support in household duties, which increases their burden (Meil 2010a). One major issue is time costs. Schneider et al. (2002a/b) noted that the lack of personal time leads to decreased physical and psychological well-being. Exhaustion and stress reactions were often reported among the highly-mobile respondents (see also Koslowsky et al. 1995; Stutzer/Frey 2008), and this could have negative effects on relationships. They concluded that those who are faced with high mobility demands (such as shuttlers, long-distance relationships, and varimobiles) are more likely to separate from their partners.

Viry et al. (2010) hypothesized that job mobility exerts an influence on conjugal satisfaction and conjugal conflict because it affects couples' cohesion and social integration. The authors expected less cohesion and social integration for shuttlers, varimobiles and other more time-consuming types of commuting. This in turn was expected to lead to lower conjugal satisfaction. However, their analysis of data from 
the European Survey on Job Mobility and Family Life did not confirm their hypothesis. Only individuals in long-distance relationships, but no individuals in any other mobility situation, reported lower conjugal satisfaction.

Although nearly one-third of respondents in the early work of Schneider also reported positive effects such as a feeling of greater autonomy within relationships, which respondents also perceived as being positive (Limmer 2005; Schneider et al. 2002a), Viry et al. (2010) and Widmer et al. (2006; 2009) argue differently. They assume that when partners are highly autonomous from each other, their conjugal quality is lower, and that more highly job-mobile couples feel more autonomous from each other. Early research supported the correlation between autonomy and mobility types. Shuttlers, varimobiles and long-distance relationships tended to perceive greater levels of partner autonomy in the relationship (Schneider et al. 2002a). But the direction of the impact of autonomy is still unclear. It could be positive for people and their partnership in which autonomy is important and job-related mobility enhances this. But it could also increase the likelihood of a separation because of the lack of time spent together. A test of these mediating effects has yet to be undertaken.

In regard to further mediating variables, Viry et al. (2010) posit that different types of mobility could generate different types of social networks. Dense networks - defined as supporting relationships common to both partners - increase the quality of intimate relationships. Long-distance relationships and shuttling, however, may have a negative impact on shared networks, presumably lowering relationship quality (Viry et al. 2010). This thesis is supported by Schneider et al. (2002a: 163), whose respondents reported deficits in social integration. Their analysis indicated that extended absence hindered the maintenance of friendships for both the mobile person and their partner. Partners of varimobiles complained about the loss of social contacts because of the scarcity of opportunities to spend time together with friends and relatives as a couple. But again, it has also been found that daily commuting facilitated social integration because commuting allows couples to spend more time together with the partner or friends compared to shuttlers or those in long-distance relationships (Schneider et al. 2002a: 188). In sum, findings from the research on job mobility and relationship quality are somewhat ambivalent and yield findings suggesting that commuting could be both supportive of and detrimental to relationship quality.

The literature offers some theoretical explanations of these contradictory results. According to Viry et al. (2010), the life course can have a mediating effect on the correlation between different types of mobility and relationship quality. Referring to previous research, they point out that job mobility is more frequent in the early stages of adulthood, during years of education, or when one just entered the job market. Thus, mobility is more typical of young people and singles, or of individuals with short-term intimate relationships. Most of these couples are childless. Partners without children are better able to cope with job mobility demands because they do not face the constraints associated with parenthood (such as child care, housework, organisation of child care arrangements, etc.). Thus Viry et al. (2010) state that "the 
impact of job mobility on conjugal quality might be weaker than expected, especially in life stages where partners are not yet parents" (Viry et al. 2010: 152).

Another theoretical consideration involves a selection problem. A large proportion of job-mobile people place a high priority on personal autonomy (Limmer 2005; Schneider et al. 2002a). Viry et al. (2010) assume that, because of the emphasis on autonomy, these people probably consider their commuting less of a burden for their relationship, and that they use the different forms of mobility to harmonise conflicting goals and expectations in separate life domains. If this is the case, starting commuting behaviour can be associated with a positive effect for individual well-being and/or for relationship quality.

\section{Theoretical remarks and hypotheses}

Previous research shows that job-related circular mobility can have a positive or negative effect on relationship quality. To elaborate this further, we use the life course approach as an overarching framework, which captures actor-specific needs and demands in a multidimensional context. In the context of the life course approach, goal-seeking behaviour is influenced by at least three dimensions: the multi-level structure of society, the multidimensionality of interdependent domains of the life course (relationship, family, work, friends, neighborhoods), and the path dependencies and trajectories of biographical decisions (Mayer 1990; Huinink/Schröder 2008). These different parts define the opportunity structure, which can be broken down into many sub-categories, and which varies over time, in space, in societies, and for each individual. Given a specific opportunity structure, individuals who have a particular set of available resources (money, time, social relations), as well as personal traits and skills, try to satisfy basic needs by pursuing appropriate goals (Huinink/Schröder 2008; Huinink/Feldhaus 2009). Note too that, in many cases, it is not possible to realise basic needs directly: People need "second-order goals" (Lindenberg/Frey 1993) or "instrumental goals" in order to realise different needs. In life course research, it is argued that, for instance, living in an intimate relationship could be an appropriate goal for reaching objectives such as affection, stimulation, and comfort (Huinink/Feldhaus 2009). This general theoretical framework is somewhat similar to other conceptual frameworks (Limmer/Schneider 2008).

In the overarching concept of life course research, job-related circular mobility is theoretically relevant in at least three different ways: (1) In regard to goal-seeking behaviour, it is a well-known fact that different types of spatial mobility are prerequisites for realising individual goals in a given opportunity structure. Thus, mobility is instrumental in goal-seeking behaviour (Kalter 1994; Schneider et al. 2002a/b; Stutzer/Frey 2008; Lück/Schneider 2010; Kley 2010; Huinink/Feldhaus 2012). (2) Jobrelated circular mobility is limited by specific parameters, related to the individual opportunity structure, such as resources, costs and benefits. Accordingly, job-related circular mobility is basically determined by distances between the place where people habitually live and the work place, by the time people need for commuting, and by resources (money, physical well-being) and opportunities (a given infrastruc- 
ture, a car, or other aspects). Furthermore, mobility increases both costs (stress, health problems, money) and at least one specific benefit (such as income, contact with colleagues, stimulation, etc.) (Stutzer/Frey 2008). These costs and benefits vary in time and space as well as with regard to each individual's specific needs. (3) Given the interdependencies of life domains, the correlation between goal-seeking behaviour and job-related circular mobility, as well as related resources, costs and benefits, it can be assumed that daily commuting influences the balance between major domains of the life course.

This shows that mobility could also have a supportive function. It enables one to achieve a specific goal or to balance two goals from different domains of the life course. In this regard, job-related circular mobility constitutes instrumental behaviour which generates new individual or relationship opportunities for goal achievement and may help individuals to harmonise conflicting demands from different domains of life (Lück/Schneider 2010; Kley 2010). On the other hand, mobility could also have a detrimental function, which is the case if, for instance, the time and money needed for commuting are then unavailable for achieving goals and satisfying demands in other domains of the life course. Similarly, stress or health problems resulting from job-related circular mobility can decrease individual well-being, which then can have a negative impact on relationship quality (Koslowsky et al. 1995). Both the supportive as well as the detrimental function may be found simultaneously, depending on which life domain one looks at. In line with this, Stutzer/ Frey (2008) stated that if commuting has extra (psychological) costs, then travelling longer distances to work is only chosen if it is either compensated by an intrinsically or financially rewarding job, or by additional welfare gained from other domains of the life course.

Thus commuting as well as other types of mobile arrangements are one part of the individual set of spatial mobility options (in addition to migration and moving) which is somewhat necessary and which integrates goal-seeking behaviour into the different domains of the life course (Limmer/Schneider 2008; Lück/Schneider 2010; Stutzer/Frey 2008; Kley 2010). Taking all this into consideration, it is not surprising that contradictory effects of mobility on relationship quality are found. The theoretical challenge, resulting from these contradictory outcomes, lies in the specification of which effects of job-related circular mobility can occur under which conditions of intimate relationships. Two mechanisms, a stress and a stimulation mechanism, are explained below.

\subsection{Stresshypothesis}

Given a sample of employed individuals living together with a partner, and controlling for job activity (full-time, part-time) as well as for educational and occupational status (factors significantly related to circular mobility, Rüger et al. 2011), it is assumed that more demanding types of job-related circular mobility, which is measured in terms of time, lead to lower relationship quality. This should be true because it generally leads to negative and resource-sapping effects. Commuting over longer distances is more time-consuming and can therefore reduce time spent 
together with the partner. It increases physical stress and lowers subjective wellbeing which - all in all - could have a negative effect on relationship quality (Koslowsky et al. 1995; Stutzer/Frey 2008). Although this should be the case for both men and women, it is argued that this negative effect should be more pronounced for women, particularly if children are living in the household. Even in this day and age, women bear more of the burden of household chores and child-rearing. Therefore, more time-consuming types of commuting may present an additional burden, in particular for mothers with young children, which increases physical stress and then leads to lower relationship quality (Press et al. 2006; Abraham/Schönholzer 2009; Lück 2010; Kley 2010).

Furthermore, as mentioned in the previous sections, job-related circular mobility could indirectly affect relationship quality. Some of these possible indirectly influenced issues are: intimacy and relatedness (Schneider et al. 2002a/b; Biehl et al. 2005; Schneider 2005), conflict (Schneider et al. 2002a/b); autonomy (Viry et al. 2010; Schneider et al. 2002a/b), or the division of labour in the household (Meil 2010a; Hofmeister/Schneider 2010). Thus, these indirectly affected relations are also included in the following analysis.

It is well documented that the quality of intimate relationships depends on feelings of intimacy and connectedness to the partner. In Deci and Ryan's self-determination theory, autonomy, intimacy and relatedness are basic needs which are essential for on-going psychological growth, integrity and well-being (2000). The degree of satisfaction in regard to intimacy and relatedness is a crucial dimension in the analysis of intimate relationships (Rüssmann/Arránz Becker 2004). Intimacy and relatedness provide a secure base for exchange processes such as emotionality, sexuality, interaction, openness, confidence or financial aspects in relationships. Thus, intimacy and relatedness or closeness and connectedness are necessary for a well-functioning relationship and are associated with a high relationship quality (Barnes/Sternberg 1997; Neff/Harter 2002). In line with previous research, this paper argues that long-distance commuting and varimobility result in higher degrees of estrangement due to a lack of time spent together with the partner. Time spent together generally leads to a higher density of interaction and increased multiplexity with the consequence of greater intimacy (Lenz 2003; Rhoades et al. 2009). Therefore, it is hypothesized that more demanding mobility reduces intimacy and relatedness, and through this mechanism has a negative impact on relationship quality.

As found in previous research, conflicts in relationships are often linked with job-related circular mobility. For instance, commuting couples often spend less time together; they are frequently exhausted from commuting, report health or financial impacts, and have difficulties in organising the housework or day care arrangements for children. They also report lower embeddedness in social networks (Widmer et al. 2009), which could generally lead to more conflicts within the relationship. Conflicts tend to lower relationship quality (Kersting/Grau 2003; Karney/ Bradbury 1995; Rüssmann/Arránz Becker 2004). Unfulfilled expectations, a lack of mutual understanding, different attitudes and emotions, daily hassles, stress and feelings of estrangement are often reported as crucial indicators of lower levels of satisfaction in intimate relationships and as predictors for separation (Kersting/Grau 
2003; Reichle/Dette-Hagenmeyer 2008; Weiss/Wagner 2008). Thus we assume more conflicts due to more time-consuming commuting behaviour which is likely to impair the quality of the relationship.

Furthermore, a more demanding commuting behaviour increases the need for a more stringent household organisation, especially for women and for mothers. Sometimes it is argued that women's mobility seems to support a more egalitarian distribution of responsibilities between partners. Nevertheless, a majority of mobile women - unlike mobile men - also have the burden of family and household work although they already shoulder the burden of work and mobility (Meil 2010b, Hofmeister/Schneider 2010). Previous research on the relationship between the division of labour and relationship satisfaction found that an absolutely equal distribution of housework is not important, but rather the perception of whether the situation as a whole is fair or unfair (e.g. Wilkie et al. 1998; Dew/Wilcox 2011). The findings support a theory of distributive justice, i.e. individuals become dissatisfied when they perceive their relationships as placing unfair burdens on them. Thus, it is hypothesized that mobile women in particular feel that they do more than their fair share because women often have the responsibility for the household even if they have to be mobile. Thus, especially for mothers, job-related circular mobility is accompanied by the perception of making a bad deal with regard to the division of household chores, which is likely to have a negative impact on the satisfaction with the relationship.

\subsection{Stimulation mechanism}

Yet, as argued from the life course perspective, different types of circular mobility could also act as facilitators for a goal-seeking behaviour. Considering empirical findings from previous research, it is argued that job-related circular mobility using the examples of commuting and varimobility could also have a positive indirect effect on relationship satisfaction, particularly with regard to perceived autonomy.

Looking again at the self-determination theory of Deci and Ryan (2000), autonomy is a basic human need. Autonomy does not refer to independence or to being separated, but rather to a state in which individuals know their own goals and try to realise them relatively unrestricted by others, while simultaneously taking care of their partner's needs. Therefore, relatedness and autonomy are not contradictory, and a well-functioning relationship is balanced on these dimensions, so that higher degrees of autonomy are also associated with a higher relationship quality (Neff/Harter 2002). Relationships in which both partners wish to retain their personal freedom and maintain autonomy lead to living arrangements characterised by higher levels of mobility and separate living arrangements. Empirical data demonstrate that for some, personal autonomy is seen as an important advantage of their present living arrangements. Shuttlers and individuals who live in long-distance relationships state that times of absence of the partner enhance personal freedom (Schneider et al. 2002b: 208). The same could be the case for people who commute daily. Being a long-distance commuter or varimobile with a high amount of nights spend away from the common household could lead to an increased feeling 
of autonomy. It might also be the case that these higher types of mobility have a stimulating effect for some people (meeting colleagues, visiting cities, time alone, etc.). Thus commuting also gives the space for doing things outside the relationship. It is hence hypothesized that perceived autonomy may have a positive effect on relationship satisfaction, which is called the stimulation mechanism - "stimulation" because autonomy is seen as a window of opportunity for doing things of interest. Particularly for women, being mobile and thus being increasingly autonomous is associated with greater freedom from the daily burden of organising the household (Nave-Herz 1994). Thus, especially for women, there are good reasons to expect that more time-consuming mobility increases the perception of autonomy to a greater extent than for men, which could then also have a positive, balancing effect on the relationship.

To put it in a nutshell, the following hypotheses are tested in the next section:

- Job-related circular mobility using the examples of daily commuting and varimobility decreases conjugal quality $(\mathrm{H} 1)$.

- These negative effects should be more pronounced for mothers (H2).

- Job-related circular mobility using the examples of daily commuting and varimobility indirectly decreases conjugal quality (mediated by intimacy, conflicts, division of household chores) (H3).

- Job-related circular mobility using the examples of daily commuting and varimobility has a positive indirect effect on conjugal quality (mediated over autonomy) (H4).

\section{$4 \quad$ Data and Methods}

The data used are from the first wave of the German "Panel Analysis of Intimate Relationships and Family Dynamics" (pairfam). This is a representative, interdisciplinary longitudinal study that aims at researching different lifestyles of people living in families or relationships in the Federal Republic of Germany conducted by Johannes Huinink, Josef Brüderl, Bernhard Nauck, and Sabine Walper and funded by the German Research Foundation (Deutsche Forschungsgemeinschaft, DFG). This 14-year long-term project aims at interviewing a group of randomly-selected individuals once a year. At the time of the first survey in 2008/2009, these individuals were categorised into representative groups aged between 15 to 17, 25 to 27, and 35 to 37 (cohort sequential design; $N=12,402$ ). Every year, if applicable the partner of the representative respondent (anchor person) and/or from the second wave on their parents or step-parents and one child living in the household are also interviewed (multi-actor design) (Huinink et al. 2011). Despite the fact that the analyses of job mobility patterns are not the major point of focus in the set of tools used in the pairfam survey, it does record central modules of job mobility in order to grasp its opportunity structure relevant for people living in relationships and families. In its approach to measure circular mobility, the data are similar to those of the first Schneider et al. (2002a/b) study and to Job Mobility and Family Life in Europe (Schneider/Meil 2008). This facilitates a comparison of both data sets (Rüger et al. 2011). 
As a panel study, pairfam thus allows to acquire data and analyse job mobility, its prerequisites, and the potential consequences that result from it with the help of a prospective cohort study design. Due to the comprehensive questionnaire and the limited amount of time available for the interviews, detailed information on the subject of mobility is only available in every second wave. In this paper we can only include information concerning job-related and partnership-related mobility for two age cohorts (25-27 and 35-37 years). The big advantage of using pairfam data to answer this question is that the content offers detailed information with regard to relationship dynamics (sociological as well as psychological measurements and scales), which are not available in the Job Mobility Project or in the German SocioEconomic Panel (SOEP).

According to Lück and Schneider (2010), mobility is defined by the fulfilment of at least one of the following criteria: (1) spending more than 60 nights during the last 12 months away from home for work-related reasons (varimobiles); (2) commuting one hour or more daily each way (long-distance commuter), (3) maintaining a long-distance relationship for work-related reasons, or (4) changing the place of residence by at least $50 \mathrm{~km}$ for work-related reasons.

In order to analyse the commuting behaviour in cohabiting relationships, we focused only on individuals who conform to criteria 1 and 2 . In line with the empirical findings, particularly from health surveys, the commuting time is used as a proxy for the burden of commuting (Koslowsky et al. 1995; Stutzer/Frey 2008). In order to obtain a better differentiation of long-distance commuting, we formed a group of medium-distance commuters, defined as people who commute 30 to 59 minutes one way to work at least three times a week (Rüger et al. 2011). This finally leads to a commuting control group of short-distance commuters (under 30 minutes one way), which also contains people who are employed but non-mobile (e.g. home office, agriculture). This provided us with main independent variables, differentiating between varimobiles, long-distance commuters (LDC), medium-distance commuters (MDC) and short-distance commuters (SDC). Short-distance commuters are the largest group (61 percent), and are therefore used as the reference category of commuting behaviour. Varimobility is also more closely related to daily commuting, and the partners share one common household. This situation is different for shuttlers or long-distance relationships due to job-related reasons. Thus, in order to receive a more balanced sample, we left these groups out and restricted the sample to employed people living together with their partners. We refer to these types because they capture a complete picture of job-related commuting behaviour.

Two items were used as dependent variables that measure general satisfaction with the relationship. The items are: "Overall, how satisfied are you with your relationship?' (ranging from $0=$ very dissatisfied to $10=$ very satisfied) and "My partner can fulfill my needs very well" (ranging from $1=$ not at all to $5=$ absolutely).

The mediating variables used were autonomy, which is measured by the following four items: "In our relationship I can usually do what I want.", "My partner finds it quite all right if I pursue my own interests in our relationship", "In our relationship I can follow my own interests without [name partner] being upset" and "I can settle my personal matters by myself without having conflicts with [name partner] about 
it" ( $1=$ not at all to $5=$ absolutely). Furthermore, relatedness is included with the two items "How often do you tell [name partner] what you're thinking?" and "How often do you share your secrets and private feelings with [name partner]?" (ranging from $1=$ never to $5=$ always). The third mediating variable is conflict, which is measured by the items "How often do you and [name partner] disagree and quarrel?" and "How often are you and [name partner] angry or furious with each other?" (1=never to $5=$ always). Finally, the perceived equity in the division of housework and labour is added as another mediating variable. The items are from $1=" I$ do much more than my fair share" to $5=" \mid$ do much less than my fair share".

There is a number of control variables related to mobility behaviour such as employment status (dummy variable with full-time and part-time employment) and occupational status (dummy variables from the ISEI scale of occupational status (Ganzeboom/Treiman 1996), which consist of three groups with values between $1=$ "0-40", 2= "41-65", and 3="66-90"). Further control variables are educational attainment (dummy variable using the casmin scale: lower=general elementary education and basic vocational training; middle=intermediate qualification, higher=tertiary education and school-leaving certificate; and finally university degree=higher tertiary education), job relevance (the respondents have to distribute 15 tokens to assess the current relevance of different domains of the life course; this item reports the number of tokens assigned to job relevance), cohort (age 25-27, or age 35-37), sex, childlessness, and marital status.

We used Structural Equation Modelling (SEM) with relationship satisfaction, autonomy, relatedness, and conflicts as latent variables. Further covariates mentioned above are included as manifest variables (Reinecke 2005; Kline 2005). The SEM structure allows including several dependent and mediating variables in one model and makes it possible to compute direct as well as indirect effects simultaneously. First, a model including the main independent variables of commuting behaviour and important covariates (models 1 and 2) is run, then the mediating variables of autonomy, relatedness, conflict and division of labour (models 3 and 4) are included. If a crucial change in the estimations of commuting variables in model 1 (or 2) compared to model 3 (or 4) regarding relationship satisfaction is found, this constitutes an initial indication of the occurrence of a mediating effect. This is also the case if the significance of the estimations changes (Frazier et al. 2004; Kenny et al. 1998; Baron/Kenny 1986). Based on the results of the third and fourth models, indirect effects are estimated (Preacher et al. 2007; Muthén 2011). Given the fact that the mediating variables are not independent from each other, the indirect effects are estimated simultaneously, a procedure called multiple mediation analysis (Preacher) Hayes 2008). Separate models were run in order to test interaction effects (e.g. sex, parenthood). If meaningful differences in the estimations were found, a Wald Test for testing the significance (Muthén/Muthén 2007; Preacher et al. 2007; Reinecke 2005) is carried out. 


\section{$5 \quad$ Results}

In regard to the initial descriptive findings, we see that in the selected sample of employed people living together with a partner, roughly 39 percent are faced with more time-consuming types of mobility, such as medium-distance commuters (22.2 percent), long-distance commuters (6.8 percent) or varimobiles (9.9 percent) (Table 1). Men are typically more intensely mobile, as was also suggested by previous research (Rüger et al. 2011). The data also show that full-time employment is more frequently associated with long-distance commuting or varimobility compared to part-time work and self-employment. These results are the same for educational attainment and occupational status: The higher the status or educational level, the greater is the chance of being a long-distance commuter or varimobile. A balanced distribution among the two cohorts is found, among the married and unmarried, and among groups with and without children. If a distinction is made between men and women, the data also provide evidence that childlessness occurs more often among women who are long-distance commuters or varimobiles, which is also a well-known result from former studies (Meil 2010b; Rüger et al. 2011).

Table 2 shows the means with regard to the dependent variables as well as for the mediating variables. Comparing different types of mobility, ${ }_{1}^{1}$ we see that highlymobile individuals, such as long-distance commuters or varimobiles, differ significantly in regard to relationship quality from low-mobile individuals. Surprisingly, we find a higher degree of satisfaction for people with a more time-consuming mobility behaviour. Looking at the mediators, the differences are not very pronounced.

Table 3 shows the results of the structural equation model for relationship quality for men and women separately. Models 1 and 2 report the results for job-related circular mobility behaviour without the mediating variables but controlled for variables correlated with job mobility. We only focus on the mobility variables. In general, there are positive effects for each job-related circular mobility type for men regarding relationship quality. The value for varimobiles is however only significant at the ten percent level. Compared to this, low negative effects of long-distance commuting and varimobility are found for women. The model fit is good for this as well as for all following models.

The focused mediating variables are then included in Models 3 and 4. Taking a first look at the job-related circular mobility variables shows substantial changes in the estimations compared to both previous models, particularly for women, which indicates the existence of mediating processes (Frazier et al. 2004). Again there are positive values for men, particularly for long-distance commuters and varimobiles with regard to relationship quality, and strong negative effects for women, with significant values for long-distance commuting women. Furthermore, all mediating variables are highly significant in the expected direction. The higher the relatedness and autonomy, and the lower the conflict level, the more satisfied respondents are with their relationships. The influence of perceived equity in the division of house-

$\overline{1}$ The reference category for the Levene $F$ test is less mobile. 
Tab. 1: Descriptive statistics of variables included ${ }^{a}$

\begin{tabular}{|c|c|c|c|c|c|c|}
\hline \multirow{4}{*}{ Variables } & \multicolumn{4}{|c|}{ Mobility types } & \multirow{3}{*}{$\begin{array}{c}\text { Sum } \\
\mathrm{N}=2,758\end{array}$} & \multirow[t]{4}{*}{ Chi'-Test } \\
\hline & $\begin{array}{c}\text { Short- } \\
\text { distance } \\
\text { commuters }\end{array}$ & $\begin{array}{l}\text { Medium- } \\
\text { distance } \\
\text { commuters }\end{array}$ & $\begin{array}{l}\text { Long- } \\
\text { distance } \\
\text { commuters }\end{array}$ & $\begin{array}{c}\text { Vari- } \\
\text { mobiles } \\
\mathrm{N}=272\end{array}$ & & \\
\hline & $\mathrm{N}=1,688$ & $\mathrm{~N}=612$ & $\mathrm{~N}=186$ & & & \\
\hline & $61.2 \%$ & $22.2 \%$ & $6.8 \%$ & $9.9 \%$ & $100 \%$ & \\
\hline \multicolumn{7}{|l|}{ Sex } \\
\hline \multirow[t]{2}{*}{ Men } & 844 & 335 & 113 & 212 & 1,504 & \\
\hline & $56.1 \%$ & $22.3 \%$ & $7.5 \%$ & $14.1 \%$ & $100 \%$ & .000 \\
\hline \multirow[t]{2}{*}{ Women } & 844 & 277 & 73 & 60 & 1,254 & \\
\hline & $67.3 \%$ & $22.1 \%$ & $5.8 \%$ & $4.8 \%$ & $100 \%$ & \\
\hline \multicolumn{7}{|l|}{ Employment } \\
\hline \multirow[t]{2}{*}{ Full-time } & 1,037 & 440 & 142 & 241 & 1,860 & \\
\hline & $58.8 \%$ & $23.7 \%$ & $7.6 \%$ & $13.0 \%$ & $100 \%$ & .000 \\
\hline \multirow[t]{2}{*}{ Part-time } & 446 & 130 & 23 & 7 & 606 & \\
\hline & $73.6 \%$ & $21.5 \%$ & $3.8 \%$ & $1.2 \%$ & $100 \%$ & \\
\hline \multirow[t]{2}{*}{ Self-employed } & 204 & 41 & 21 & 24 & 290 & \\
\hline & $70.3 \%$ & $14.1 \%$ & $7.2 \%$ & $8.3 \%$ & $100 \%$ & \\
\hline \multicolumn{7}{|l|}{ Education } \\
\hline \multirow[t]{2}{*}{ Lower } & 334 & 79 & 25 & 40 & 478 & \\
\hline & $69.9 \%$ & $16.5 \%$ & $5.2 \%$ & $8.4 \%$ & $100 \%$ & .000 \\
\hline \multirow[t]{2}{*}{ Middle } & 650 & 202 & 61 & 104 & 1,017 & \\
\hline & $63.9 \%$ & $19.9 \%$ & $6.0 \%$ & $10.2 \%$ & $100 \%$ & \\
\hline \multirow[t]{2}{*}{ Higher } & 290 & 131 & 33 & 52 & 506 & \\
\hline & $57.3 \%$ & $25.9 \%$ & $6.5 \%$ & $10.3 \%$ & $100 \%$ & \\
\hline \multirow[t]{2}{*}{ University } & 413 & 200 & 68 & 77 & 758 & \\
\hline & $54.4 \%$ & $26.4 \%$ & $9.0 \%$ & $10.2 \%$ & $100 \%$ & \\
\hline \multicolumn{7}{|l|}{ ISEI $^{\mathrm{b}}$} \\
\hline \multirow[t]{2}{*}{$0-40$} & 800 & 238 & 65 & 134 & 1,237 & \\
\hline & $65.0 \%$ & $19.0 \%$ & $5.0 \%$ & $11.0 \%$ & 100 & .000 \\
\hline \multirow[t]{2}{*}{$41-65$} & 637 & 234 & 73 & 78 & 1,022 & \\
\hline & $62.3 \%$ & $22.9 \%$ & $7.1 \%$ & $7.6 \%$ & $100 \%$ & \\
\hline \multirow[t]{2}{*}{$66-90$} & 250 & 140 & 49 & 61 & 500 & \\
\hline & $50 \%$ & $28.0 \%$ & $9.8 \%$ & $12.2 \%$ & $100 \%$ & \\
\hline \multicolumn{7}{|l|}{ Cohort } \\
\hline \multirow[t]{2}{*}{$25-27$ years } & 575 & 198 & 66 & 84 & 923 & \\
\hline & $62.3 \%$ & $21.5 \%$ & $7.2 \%$ & $9.1 \%$ & $100 \%$ & .622 \\
\hline $35-37$ years & 1,113 & 414 & 120 & 188 & 1,835 & \\
\hline & $60.7 \%$ & $22.6 \%$ & $6.5 \%$ & $10.2 \%$ & $100 \%$ & \\
\hline Childless & & & & & & \\
\hline Yes & 728 & 306 & 98 & 138 & 1,270 & \\
\hline & $57.3 \%$ & $24.1 \%$ & $7.7 \%$ & $10.9 \%$ & $100 \%$ & .002 \\
\hline No & 959 & 306 & 88 & 135 & 1,488 & \\
\hline & $64.4 \%$ & $20.6 \%$ & $5.9 \%$ & $9.1 \%$ & $100 \%$ & \\
\hline Married & & & & & & \\
\hline Yes & 1,108 & 387 & 113 & 165 & 1,773 & \\
\hline & $62.5 \%$ & $21.8 \%$ & $6.4 \%$ & $9.3 \%$ & $100 \%$ & .220 \\
\hline No & 580 & 225 & 73 & 108 & 986 & \\
\hline & $58.8 \%$ & $22.8 \%$ & $7.4 \%$ & $11.0 \%$ & $100 \%$ & \\
\hline
\end{tabular}

a For the description we use the dxpsweight; see Brüderl et al. 2010; this reduces the sample size from 3,117 to 2,758 .

b International Socio-Economic Index of Occupational Status (Ganzeboom/Treimann 1996).

Source: pairfam-data, wave 1 
Tab. 2: $\quad$ Means (standard deviation in brackets) of dependent and mediating variables

\begin{tabular}{|c|c|c|c|c|}
\hline & \multicolumn{4}{|c|}{ Mobility Types } \\
\hline & $\begin{array}{l}\text { Short- } \\
\text { distance } \\
\text { commuters }\end{array}$ & $\begin{array}{l}\text { Medium- } \\
\text { distance } \\
\text { commuters }\end{array}$ & $\begin{array}{l}\text { Long-distance } \\
\text { commuters }\end{array}$ & Varimobiles \\
\hline & $=$ Reference & & & \\
\hline Satisfaction & $7.82(1.94)$ & $7.96(1.66)^{* * *}$ & $7.97(1.85)+$ & $8.04(1.68)^{* *}$ \\
\hline Relatedness & $3.82(0.78)$ & $3.88(0.70)^{* *}$ & $3.85(0.76)$ & $3.76(0.74)$ \\
\hline Autonomy & $3.63(0.81)$ & $3.67(0.77)^{*}$ & $3.54(0.76)$ & $3.56(0.75)$ \\
\hline Conflict & $2.59(0.65)$ & $2.54(0.64)$ & $2.42(0.56)^{*}$ & $2.55(0.60)$ \\
\hline Division of housework and labour & $2.85(0.71)$ & $2.91(0.66)^{*}$ & $2.93(0.71)$ & $3.08(0.68)$ \\
\hline
\end{tabular}

$* * *<.001, * *<.01, *<.05,+<.10$

Source: pairfam-data, wave 1

work and labour for the relationship satisfaction is also seen. Men and women who think they do less than their fair share are more satisfied with their relationship. Regarding included covariates, we find that both childless and married men are significantly more satisfied with their relationships. For women, we found that more highly-educated women as well as women of the younger cohort report lower relationship quality.

In the description and explanation of stress mechanisms (Hypothesis 1) which could come along with job-related circular mobility, it is assumed that long-distance commuting and varimobility should be associated with a negative effect for men and women with regard to relationship quality. The data show that this hypothesis is only confirmed for women, but not for men. The effect differences for long-distance commuters $(p=0.027)^{2}$ as well as for varimobiles $(p=0.023)$ are significant between men and women in Models 3 and 4.

Furthermore, it is argued that the negative effect of job-related circular mobility for relationship quality should be stronger for women compared to men, particularly if there are children in the household (Hypothesis 2). This mechanism is confirmed by the data in Models 5 and 6 . Both models only include people with children under the age of 18 in the household, hence reducing the sample size. The effects are similar to the previous models. Women who are long-distance commuters or varimobiles report lower relationship satisfaction compared to men (both differences are significant; $p=0.014$ for LDC; $p=0.016$ for varimobiles). If a model with only childless women is estimated (results not shown), then the negative effects disappear, thus this effect is closely associated with the status of being a mother who is commut-

2 Structural Equation Modelling offers the opportunity to carry out a multiple group analysis and to compare (by using a $\mathrm{Chi}^{2}$-Wald test) whether the effects are statistically different from each other (see Reineke 2005). In the multiple group analysis the whole model is estimated for each group separately (here men and women). 
Tab. 3: $\quad$ Structural equation model of effects on relationship quality for men and women (age 25-27; 35-37; employed persons)

\begin{tabular}{|c|c|c|c|c|c|c|}
\hline & \multicolumn{6}{|c|}{ Satisfaction } \\
\hline & Model 1 & Model 2 & Model 3 & Model 4 & Model 5 & Model 6 \\
\hline & Men & Women & Men & Women & Men & Women \\
\hline & & & & & with childre & 18 in $\mathrm{HH}$ \\
\hline \multicolumn{7}{|c|}{ Independent variables (ref.: short-distance commuters) } \\
\hline Medium-distance commuters & 0.089 & 0.030 & 0.027 & -0.022 & 0.118 & -0.003 \\
\hline Long-distance commuters & 0.183 & -0.034 & 0.150 & $-0.299 *$ & 0.194 & $-0.472 *$ \\
\hline Varimobiles & $0.187+$ & -0.074 & $0.200^{*}$ & -0.255 & $0.263^{*}$ & $-0.537+$ \\
\hline \multicolumn{7}{|l|}{ Mediating variables } \\
\hline Relatedness & & & $0.820 * * *$ & $0.913 * * *$ & $0.838 * * *$ & $0.894 * * *$ \\
\hline Autonomy & & & $0.612 * * *$ & $0.735^{* * *}$ & $0.815^{* *}$ & $0.747 * * *$ \\
\hline Conflicts & & & $-0.629 * * *$ & $-0.879 * * *$ & $-0.696 * * *$ & $-0.983 * * *$ \\
\hline Division of labour & & & $0.158 * *$ & $0.154^{* *}$ & 0.084 & $0.190 * * *$ \\
\hline \multicolumn{7}{|l|}{ Control variables } \\
\hline \multicolumn{7}{|l|}{ CASMIN (ref.: lower) } \\
\hline CASMIN medium & 0.118 & -0.167 & 0.086 & $-0.285^{* *}$ & 0.033 & $-0.398 * *$ \\
\hline CASMIN higher & 0.161 & -0.144 & 0.123 & $-0.286^{*}$ & 0.050 & $-0.383^{*}$ \\
\hline CASMIN university degree & 0.151 & -0.137 & 0.136 & $-0.315^{*}$ & 0.078 & $-0.450+$ \\
\hline \multicolumn{7}{|l|}{ Part-time } \\
\hline (ref.: full-time/self-empl.) & 0.052 & 0.066 & -0.152 & 0.038 & -0.128 & -0.009 \\
\hline ISEI 41-65 (ref.: ISEI 16-40) & -0.048 & -0.052 & -0.022 & -0.078 & 0.041 & -0.052 \\
\hline ISEI 66-90 (ref.: ISEI 16-40) & $-0.213+$ & 0.059 & -0.174 & -0.048 & -0.145 & -0.157 \\
\hline Job relevance & -0.004 & $-0.061^{*}$ & 0.027 & -0.001 & $0.054^{*}$ & 0.020 \\
\hline Cohort 1971/73 (ref.: 1981/83) & -0.095 & $-0.160+$ & -0.090 & $-0.161 *$ & 0.126 & 0.009 \\
\hline Childless (ref.: with child(ren)) & $0.382 * * *$ & $0.421 * * *$ & $0.247 * *$ & 0.059 & - & - \\
\hline Married (ref.: not married) & $0.277^{* *}$ & 0.141 & $0.266 * *$ & 0.120 & 0.154 & 0.036 \\
\hline $\mathrm{Chi}^{2} / \mathrm{df} / \mathrm{p}$ & \multicolumn{2}{|c|}{$514.562 / 58 / 0.000$} & \multicolumn{2}{|c|}{$780.791 / 332 / 0.000$} & \multicolumn{2}{|c|}{$524.937 / 292 / 0.000$} \\
\hline CFI/ RMSEA/SRMR ${ }^{a}$ & \multicolumn{2}{|c|}{$0.965 / 0.020 / 0.009$} & \multicolumn{2}{|c|}{$0.927 / 0.030 / 0.033$} & \multicolumn{2}{|c|}{$0.933 / 0.029 / 0.032$} \\
\hline$N=$ & 1,619 & 1,493 & 1,619 & 1,493 & 989 & 880 \\
\hline
\end{tabular}

a The CFI is a comparative fit index. It assesses the relative improvement in the fit of the researcher's model compared with a baseline model (the independence model), which assumes zero population covariances among the observed variables. The expected unrelated variables lead to a high chi square. The improvement of the model is better to the extent that the researcher's model reduces this chi square. If we have no improvement, it makes no sense to accept the researcher's model. The CFI should be higher than 0.90. RMSEA (root mean square error of approximation) is a "badness of fit" index in that a value of zero indicates the best fit. RMSEA estimates the amount of error of approximation per model degree of freedom and takes the sample size into account. RMSEA $<0.05$ indicates close approximate fit. Finally, the SRMR (standardised root mean squared residual) is based on transforming both the sample covariance matrix and the predicted covariance matrix into correlation residuals. Values less than 0.10 , or even better 0.05 , are generally considered favorable (Kline 2005). These models are calculated without any weights, this explains why $\mathrm{N}$ is at 3117 again like in the original sample. Five cases had to be excluded due to missing values.

$* * * .001 .{ }^{* *}<.01 .{ }^{*}<.05 .+<.10$

Source: pairfam-data, wave 1

ing over a long distance or a varimobile. Thus, we assume that this direct negative effect, particularly for mothers, is associated with a higher burden in regard to organising the household and child-rearing. The exhausting situation increases with higher commuting times, which is additionally accompanied by greater stress, fatigue and/or health problems. 
In order to test the following mechanisms (Hypothesis 3 ), it is necessary to compute indirect effects. Comparing the models (1 to 4$)$ and their estimations, only small changes are found for men between Models 1 and 3 , but there are more pronounced effects for women (Models 2 and 4). This indicates that job-related circular mobility behaviour is correlated with the mediating variables included, particularly for women. Therefore a mediation analysis, shown in Figure 1, is carried out by running two regressions: Firstly, relationship quality is regressed on mobility types, controlled for other covariates (estimations for men and women are shown in Models 3 and 4). Subsequently, a regression of the mediating variable on job-related circular mobility behaviour is carried out (which is shown in Table 4 for each type of job-related circular mobility and each mediating variable). The product of both regression effects is the resulting indirect effect (see Fig. 1 and the values in brackets in Table 4), which is also tested for significance. This mediation analysis is carried out simultaneously for all mediators included, a procedure known as multiple mediation analysis (Preacher/Hayes 2008).

Focusing on the indirect effect of relatedness for men, we find no evidence to support the stress mechanism stating that more time-consuming mobility behaviour lowers intimacy and relatedness. Job-related circular mobility, such as medium-distance and long-distance commuting, as well as varimobility, does neither appear to lower the perceived intimacy and relatedness nor to have a negative impact on relationship satisfaction. For women, the opposite is true: Long-distance commuting as well as varimobile women report that these types of mobility are accompanied by a higher degree of relatedness to the partner, which in sum has a weak significant positive effect on relationship quality. No effect is found for men, and the difference between men and women is not significant for long-distance commuters $(p=0.228)$

Fig. 1: Direct and indirect effects between conflicts and relationship quality for long-distance commuting (LDC) women

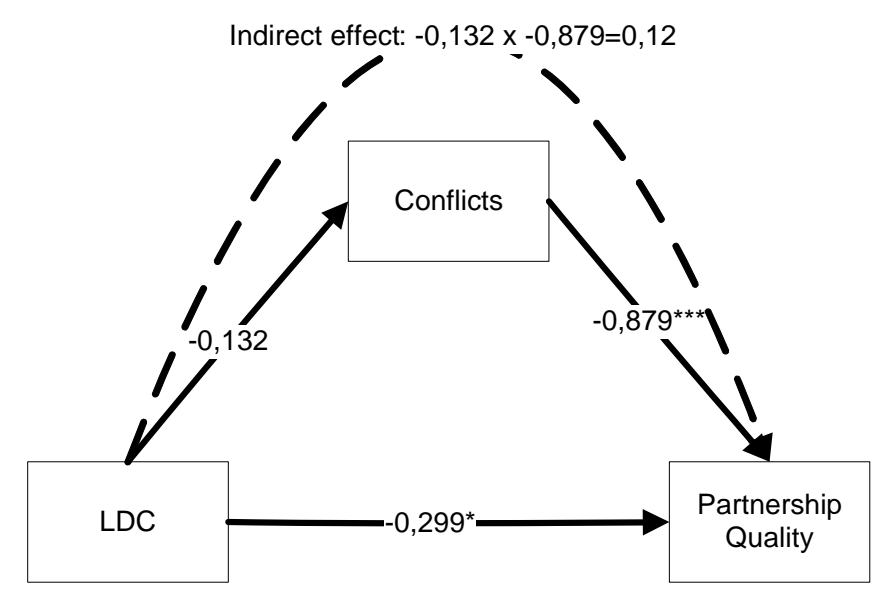

Source: pairfam-data, wave 1 
Tab. 4: Estimation of the regression of included mediators on job-related circular mobility behaviour (indirect effects in brackets)

\begin{tabular}{lcccr}
\hline & & \multicolumn{2}{c}{ Mediators } & \\
& Relatedness & Autonomy & Conflict & $\begin{array}{r}\text { Division of } \\
\text { housework } \\
\text { and labour }\end{array}$ \\
\hline Men & & & & \\
Medium-distance commuters & 0.042 & 0.011 & -0.010 & 0.014 \\
(ref.: short-distance commuters) & $(0.033)$ & $(0.007)$ & $(0.007)$ & $(0.002)$ \\
Long-distance commuters & -0.008 & -0.051 & $-\mathbf{0 . 0 9 6}+$ & 0.019 \\
(ref.: short-distance commuters) & $(-0.007)$ & $(-0.031)$ & $(\mathbf{0 . 0 6 0 ) +}$ & $(0.003)$ \\
Varimobiles & -0.048 & 0.019 & -0.009 & 0.059 \\
(ref.: Short-distance commuters) & $(-0.039)$ & $(0.012)$ & $(0.006)$ & $(0.009)$ \\
N=1,619 & & & & \\
\hline Women & & & & \\
Medium-distance commuters & 0.061 & $\mathbf{0 . 0 6 8 +}$ & -0.011 & 0.038 \\
(ref.: short-distance commuters) & $(0.056)$ & $\mathbf{( 0 . 0 5 0 ) +}$ & $(0.010)$ & $(0.006)$ \\
Long-distance commuters & $\mathbf{0 . 1 3 1 +}$ & $\mathbf{0 . 1 3 5 +}$ & $-\mathbf{0 . 1 3 2}+$ & 0.081 \\
(ref.: short-distance commuters) & $\mathbf{( 0 . 1 2 0 ) +}$ & $\mathbf{( 0 . 0 9 9 ) +}$ & $\mathbf{( 0 . 1 2 0 ) +}$ & $(0.012)$ \\
Varimobiles & $\mathbf{0 . 1 4 8 +}$ & $\mathbf{0 . 1 0 9}$ & -0.073 & 0.100 \\
(ref.: Short-distance commuters) & $\mathbf{( 0 . 1 3 5 ) +}$ & $(0.079)$ & $(0.064)$ & $(0.015)$ \\
N=1,493 & & & & \\
\hline
\end{tabular}

$* * *<.001{ }^{* *}<.01 .{ }^{*}<.05 .+<.10$

Source: pairfam-data, wave 1

but it is for varimobiles $(p=0.043)$. These results somewhat contradict the given theoretical assumption, although it is controlled for other important job-related variables (see table 1 and Models 3 and 4 in Table 3).

Similar results are found for intra-relationship conflicts. It is assumed in the description and explanation of stress mechanisms that conflicts are more prevalent due to circular mobility, which should lead to lower relationship quality. Again, this could not be confirmed. Instead we found empirical support for a positive influence of long-distance commuting on decreasing conflicts, which then affects relationship quality in a positive way. This is the same for both men and women. Thus, while conflict directly reduces relationship quality, especially long-distance commuting is linked to a lower conflict incidence, which in turn has a positive and significant effect on the relationship. This result seems to support the findings of other empirical studies which have shown that in relationships with higher forms of mobility, the shared time is regarded as very valuable (Schneider et al. 2002a). If time is seen as very valuable, then frequent absences and less time spent together as a result of 
commuting might decrease conflicts over daily hassles because couples seek to maximise enjoyment of the limited amount of time spent together.

In regard to the stress mechanisms, it is also argued that especially for women, job-related circular mobility is associated with a perception of an unfair share of housework and labour because women take more responsibility for the household and are more burdened with mobility behaviour, which is likely to have a negative impact on satisfaction with the relationship. This is, however, not confirmed by the data.

Finally, focusing on the stimulation mechanism (Hypothesis 4), it is suggested that especially for women job-related circular mobility is accompanied by a higher perception of autonomy, which could also have a positive impact on relationship quality. Empirical evidence indeed supports this mechanism, particularly for women. If they commute over medium-distances, long-distances, or if they are varimobiles, these mobility types have on the whole a positive indirect effect on the perception of relationship autonomy, which increases relationship satisfaction. The differences between men and women are only significant for LDC $(p=0.044)$.

It is possible to sum up the cross-sectional analysis as follows: Hypothesis 1 which says that job-related circular mobility decreases conjugal quality is partly confirmed. The data only support the stress mechanism of a direct negative effect on relationship quality for job-related mobility for women and for mothers in particular (Hypothesis 2), whilst for men there are direct positive effects of job-related mobility with regard to relationship quality. We also find that job-related circular mobility is not associated with lower relatedness or more conflict behaviour in relationships. The opposite in fact happens: There is empirical evidence to suggest that, particularly for women, more demanding mobility actually has a positive influence on the perceived autonomy within the relationship, which has a positive effect on relatedness, and lowers perceived conflicts with the partner. Altogether, this interacts positively with relationship quality. Interestingly, for women, both direct negative effects of commuting behaviour and indirect positive effects via relatedness, autonomy and conflicts on relationship quality are found (Hypotheses 3 and 4). For men, only positive direct effects of commuting on relationship quality occur. Note that other job-related variables are controlled for, which means that these effects are not the results of job-related status variables.

\section{Conclusion}

This paper addresses the influence of different types of job-related mobility on couples' relationship satisfaction. Following cues from previous research, it is useful to distinguish between direct and indirect effects as well as to investigate it separately for men and women.

In our cross-sectional analysis, the data only support the stress mechanisms hypothesis of a negative effect on relationship quality for more demanding mobility types such as long-distance commuters and varimobiles for women, and for mothers in particular. This finding confirms previous research of a heavier burden 
for women if they have young children and for instance have to commute over long distances. As Meil (2010a) and Hofmeister/Schneider (2010) emphasize, despite the fact that women's mobility seems to support a more egalitarian distribution of responsibilities between partners, a majority of women continue to shoulder the burden of organising the family while working and being mobile. Surprisingly, this is not reflected in the mediating effect of the division of household work. The indicator of the perceived fairness of the division of labour probably does not work all that well for this question, and it would be better to attempt to gather information on the factual distribution of housework tasks in future research.

Positive effects of job-related circular mobility in regard to relationship quality are found for men, and these effects are more pronounced if children are present. The differences between men and women are significant. For men, it is assumed that commuting enables them to combine both job and family, which means that they do not have to do without a family, but they become less burdened because they reduce their engagement in household-related tasks and daily parental responsibilities. This partly supports the thesis of a traditionalising effect of men's mobility on the household division of labour (Meil 2010b), but further research is needed, particular from the longitudinal perspective.

Furthermore, our results support empirical evidence of the usefulness of including more mediating variables for disentangling the connection between job-related circular mobility and relationship quality, as argued by Viry et al. (2010). It is seen that mobility behaviour is not - as had been assumed - significantly associated with lower relatedness or higher conflict behaviour in relationships. The data show that, particularly for women, more demanding mobility types are associated with higher degrees of perceived autonomy within the relationship, as well as in regard to relatedness. Furthermore, it correlates with fewer perceived conflicts with the partner, which in sum results in a positive effect on relationship quality.

Thus for women both direct negative effects of job-related circular mobility, in support of the stress mechanisms, as well as indirect positive effects via relatedness, autonomy and conflicts on relationship quality are found, which also supports the mechanism of stimulation. This may seem a contradiction in terms, but as is also shown by Reuschke for long-distance relationships (2010), women mentioned negative effects in regard to stress and health but positive effects in regard to relationship quality. Similarly, Collet and Dauber (2010) found that mobile women are more concerned with negative psychological consequences than mobile men in the sense of being pressed for time, the feeling of being depressed, and being tired and exhausted (Collet/Dauber 2010: 185). Thus it seems that job-related circular mobility increases the daily burden, particularly for women and mothers, which leads to lower subjective well-being and, in turn, to lower relationship quality. On the other hand, mobility behaviour could be associated with higher relatedness, autonomy, and fewer conflicts, and this has a positive effect on relationship quality. Here however we have to mention a limitation of this analysis: We only looked from the crosssectional perspective, because the opportunity for a longitudinal analysis, including mediating variables, is so far restricted. Here we need further analysis in order to see what the causality behind this correlation is and how the results might look like 
in the long run: Does long-distance commuting or varimobility increase relationship instability in the long run - as our results of direct negative effects for women indicate? There is still another problem regarding indications of causality: Job-related mobility behaviour could increase relatedness and autonomy, or reduce conflicts. But it is also possible that people who have higher values regarding these dimensions are more willing to accept more time-consuming types of job-related mobility behaviour because they know that their relationship will cope with this in a satisfying way. Then, the connection between job-related mobility and relationship satisfaction is rather based on a moderating effect than on a mediating effect. Further, particularly longitudinal research is needed here.

The analysis shows that the "commuting paradox", mentioned by Stutzer and Frey (2008) in the sense that commuting behaviour leads to a lower subjective wellbeing in the long run while it simultaneously offers other benefits (job status, income), could be somewhat disentangled if benefits and costs of other life domains are also considered.

\section{References}

Abraham, Martin; Auspurg, Katrin; Hinz, Thomas 2010: Migration decisions within dualearner partnerships: a test of bargaining theory. In: Journal of Marriage and the Family 72: 876-892 [doi>10.1111/j.1741-3737.2010.00736.x].

Abraham, Martin; Schönholzer, Thess 2009: Pendeln oder Umziehen? Entscheidungen über unterschiedliche Mobilitätsformen in Paarhaushalten. In: Kriwy, Peter; Gross, Christiane (Eds.): Klein aber fein! Quantitative empirische Sozialforschung mit kleinen Fallzahlen. Wiesbaden: VS: 247-268.

Barnes, Michael L.; Sternberg, Robert J. 1997: A hierarchical model of love and its prediction of satisfaction in close relationships. In: Sternberg, Robert J.; Hojjat, Mahzat (Eds.): Satisfaction in Close Relationships. New York/London: The Guilford Press: 79-102.

Baron, Reuben M.; Kenny, David A. 1986: The moderator-mediator distinction in social psychological research: Conceptual, strategic and statistical considerations. In: Journal of Personality and Social Psychology 51,6: 1173-1182.

Biehl, Heiko; Keller, Jörg; Tomforde, Maren 2005: Den eigentlichen Einsatz fährt meine Frau zu Hause. Belastungen von Bundeswehr-Soldaten und ihren Familien während des Auslandeinsatzes. In: Kümmel, Gerhard (Eds.): Diener zweier Herren: Soldaten zwischen Bundeswehr und Familie. Frankfurt am Main: Lang: 79-107.

Blossfeld, Hans-Peter; Drobnic, Sonja 2002: Careers of Couples in Contemporary Society: From Male Breadwinner to Dual-Earner Families. New York: Oxford University Press.

Brüderl, Josef; Castiglioni, Laura; Krieger, Uli; Ludwig, Volker; Pforr, Klaus; Schumann, Nina 2010: pairfam Data Manual, Wave 1. Mannheim.

Bunker, Barbara B.; Vanderslice, Virginia J.; Rice, Robert W. 1992: Quality of Life in Dual-Career Families: Commuting Versus Single-Residence Couples. In: Journal of Marriage and the Family 54,2: 399-407. 
Collet, Beate; Dauber, Andrea 2010: Gender and Job Mobility. In: Schneider, Norbert F.; Collet, Beate (Eds.): Mobile Living Across Europe II. Opladen/Farmington Hills: Barbara Budrich Publishers: 173-194.

Deci, Edward L.; Ryan, Richard M. 2000: The "what" and "why" of goal pursuits: Human needs and the self-determination of behavior. In: Psychological Inquiry 4: 227-268.

Dew, Jeffrey; Wilcox, W. Bradford 2011: If Momma Ain't Happy: Explaining Declines in Marital Satisfaction Among New Mothers. In: Journal of Marriage and Family 73,1: 1-12 [doi: 10.1111/j.1741-3737.2010.00782.x].

Dickinson, Robert E. 1959: The geography of commuting in West Germany. In: Annals of the Association of American Geographers 49: 443-456.

Esser, Hartmut 1993: Allgemeine Soziologie. Frankfurt/M.: Campus.

Frazier, Patrizia A.; Tix, Andrea P.; Barron, Kenneth E. 2004: Testing moderator and mediator effects in counselling psychology research. Journal of Counselling Psychology 51: $15-134$

Ganzeboom, Harry B.G.; Treiman, Donald J. 1996: Internationally comparable measures of occupational status for the 1988 international standard classification of occupations. In: Social Science Research 25: 201-239.

Hofmeister, Heather; Schneider, Norbert F. 2010: Job Mobilities in Europe: Core Findings, Policy Implications and Future Outlook. In: Schneider, Norbert F.; Collet, Beate (Eds.): Mobile Living Across Europe II. Opladen/Farmington Hills: Barbara Budrich Publishers: 337-356.

Huinink, Johannes; Schröder, Torsten 2008: Skizzen zu einer Theorie des Lebensverlaufs. In: Diekmann, Andreas; Eichner, Klaus; Schmid, Peter; Voss, Thomas (Eds.), Rational Choice: Theoretische Analysen und empirische Resultate. Wiesbaden: VS Verlag für Sozialwissenschaften: 291-308.

Huinink, Johannes; Feldhaus, Michael 2009: Family Research from the Life Course Perspective. In: International Sociology 24,3: 299-324 [doi: 10.1177/0268580909102910].

Huinink, Johannes et al. 2011: Panel Analysis of Intimate Relationships and Family Dynamics (pairfam): Framework and Design of pairfam. In: Zeitschrift für Familienforschung, 23: 77-101 [doi:10.4232/pairfam.5678.3.1.0].

Kalter, Frank 1994: Pendeln statt Migration. In: Zeitschrift für Soziologie 23: 460-476.

Kalter, Frank 1997: Wohnortswechsel in Deutschland. Ein Beitrag zur Migrationstheorie und zur empirischen Anwendung von Rational-Choice Modellen. Opladen: Leske + Budrich.

Kaufmann, Vincent; Widmer, Eric D. 2006: Motility and family dynamics: current issues and research agendas. In: Zeitschrift für Familienforschung 18: 111-129.

Karney, Benjamin R; Bradbury, Thomas 1995: The longitudinal course of marital quality and stability: A review of theory, method, and research. In: Psychological Bulletin 118,1: 3-34.

Kenny, David A.; Kashy, Deborah, A.: Bolger, Niall 1998: Data analysis in social psychology. In: Gilgert, Daniel Todd; Fiske, Susan T.; Lindzey, Gardner (Eds.): The handbook of social psychology. New York: Oxford University: 233-264.

Kersting, Jens; Grau, Ina 2003: Paarkonflikt und Trennung. In: Grau, Ina; Bierhoff, HansWerner (Eds.): Sozialpsychologie der Partnerschaft. Heidelberg: Springer: 426-457.

Kley, Stefanie 2010: Multilokalität als Strategie zur Nutzung von Chancen. In: Soeffner, Hans-Georg (Eds.): Unsichere Zeiten: Herausforderungen und gesellschaftliche Transformationen. Wiesbaden: VS Verlag. CD-Rom. 
Kline, Rex B. 2005: Principles and Practices of Structural Equation Modeling. New York: Guilford Press.

Koslowsky, Meni; Kluger, Avraham N.; Reich, Mordechai 1995: Commuting Stress. New York: Plenum Press.

Lenz, Karl 2003: Soziologie der Zweierbeziehung. Wiesbaden: VS Verlag.

Limmer, Ruth 2005: Berufsmobilität und Familie in Deutschland. In: Zeitschrift für Familienforschung 17: 8-26.

Limmer, Ruth, Schneider, Norbert F. 2008: Studying Job-Related Spatial Mobility in Europe. In: Schneider, Norbert F.; Meil, Gerardo (Eds.): Mobile Living Across Europe I. Relevance and Diversity of Job-Related Spatial Mobility in Six European Countries. Opladen/Farmington Hills: Barbara Budrich Publishers: 13-46.

Lindenberg, Siegwart 1989: Social Production Functions, Deficitsm and Social Revolutions. In: Rationality and Society 1: 51-77.

Lindenberg, Siegwart; Frey, Bruno 1993: Alternatives, frames, and relative prices: a broader view of rational choice. In: Acta Sociologica 36: 191-205.

Lück, Detlev 2010: Walking the tighttrope. Combining family life, career and job mobility. In: Zeitschrift für Familienforschung 22: 216-241.

Lück, Detlev; Schneider, Norbert F. 2010: Introduction to the special issue on Mobility and family: Increasing job mobility - changing family lives. In: Zeitschrift für Familienforschung 22,2: 135-148.

Mayer, Karl Ulrich 1990: Lebensverläufe und sozialer Wandel - Anmerkungen zu einem Forschungsprogramm. In: Mayer, Karl Ulrich (Eds.): Lebensverläufe und sozialer Wandel. In: Kölner Zeitschrift für Soziologie und Sozialpsychologie, Sonderheft 31: 7-21.

Meil, Gerado 2010a: Job Mobility and Family Life. In: Schneider, Norbert F.; Collet, Beate (Eds.): Mobile Living Across Europe II. Opladen/Farmington Hills: Barbara Budrich Publishers: 215-237.

Meil, Gerado 2010b: Geographic job mobility and parenthood decisions. In: Zeitschrift für Familienforschung 22: 171-196.

Muthén, Linda; Muthén, Bengt 1998-2007: Mplus User's Guide. Fifth Edition. Los Angeles.

Muthén, Bengt 2011: Applications of Causally Defines Direct and Indirect Effekts in Mediation Analysis using SEM in MPLUS (under Review).

Nave-Herz, Rosemarie 1994: Frauen zwischen Tradition und Moderne. Bielefeld: Kleine Verlag.

Neff; Kristin; Harter, Susan 2002: Relationships Styles of Self-Focused Autonomy, OtherFocused Connectedness, and Mutuality across Multiple relationship Contexts. In: Journal of Social and Personal Relationships 20,1: 81-99.

Ommeren, Jos van 1998: On-the-Job Search Behavior: The Importance of Commuting Time. In: Land Economics 74: 526-540.

Preacher, Kristopher J.; Rucker, Derek D.; Hayes, Andrew F. 2007: Addressing Moderated Mediation Hypotheses: Theory, Methods, and Prescriptions. In: Multivariate Behavioral Research 42: 185-227.

Preacher, Kristopher J.; Hayes, Andrew F. 2008: Asymptotic and Resampling Strategies for Assessing and Comparing Indirect Effects in Multiple Mediator Models. In: Behavior Research Methods 40: 879-891 [doi: 10.3758/BRM.40.3.879]. 
Press, Julie E.; Fagan, Jay; Laughlin, Lynda 2006: Taking Pressure off Families: ChildCare Subsidies Lessen Mother's Work-Hour Problems. In: Journal of Marriage and the Family 68: 155-171 [doi: 10.1111/j.1741-3737.2006.00240.x].

Reichle, Barbara; Dette-Hagenmeyer, Dorothea 2008: Individuelle und dyadische Bewältigung von Alltagskonflikten: Themen, Copingstrategien und Partnerschaftsqualität. In: Feldhaus, Michael; Huinink, Johannes (Eds.): Neuere Entwicklungen in der Beziehungs- und Familienforschung. Würzburg: Ergon: 229-257.

Reinecke, Jost 2005: Strukturgleichungsmodelle. München: Oldenbourg.

Reuschke, Darja 2010: Multilokales Wohnen. Wiesbaden: VS Verlag.

Rhoades, Galena K.; Scott M. Stanley; Markman, Howard J. 2009: Couples' Reasons for Cohabitation. Associations With Individual Well-Being and Relationship Quality. In: Journal of Family Issues 30,2: 233-258 [doi:10.1177/0192513X08324388].

Rüger, Heiko; Limmer, Ruth 2010: Job Mobilities and Quality of Life. In: Schneider, Norbert F.; Collet, Beate (Eds.): Mobile Living Across Europe II: Causes and Consequences of Job-Related Spatial Mobility in Cross-National Comparison. Opladen: Barbara Budrich: 263-288.

Rüger, Heiko; Feldhaus, Michael; Becker, Katharina; Schlegel, Monika 2011: Zirkuläre berufsbezogene Mobilität in Deutschland: Vergleichende Analysen mit zwei repräsentativen Surveys zu Formen; Verbreitung und Relevanz im Kontext der Partnerschaftsund Familienentwicklung In: Comparative Population Studies - Zeitschrift für Bevölkerungswissenschaft 36,1: 193-220 [doi: 10.4232/10.CPoS-2011-05de].

Rüssmann, Karin; Arránz Becker, Oliver 2004: Die Interdependenz von Sozialstruktur, Familienzyklus, Interaktionsstil und Partnerschaftszufriedenheit. In: Hill, Paul B. (Eds.): Interaktion und Kommunikation. Eine empirische Studie zu Alltagsinteraktion, Konflikten und Zufriedenheit in Partnerschaften. Würzburg: Ergon: 207-249.

Schmahl, Franziska et al. 2012: Scales. Manual wave 1 to 3. Technical report.

Schneider, Norbert F. 2005: Leben an zwei Orten. Die Folgen beruflicher Mobilität für Familie und Partnerschaft. In: Mischau, Anina; Oechs/e, Mechtild (Eds.): Arbeitszeit Familienzeit - Lebenszeit: Verlieren wir die Balance? Zeitschrift für Familienforschung, Sonderheft 5. Wiesbaden: VS Verlag: 110-126.

Schneider, Norbert F.; Limmer, Ruth; Ruckdeschel, Kerstin 2002a: Mobil, flexibel, gebunden. Frankfurt/M.: Campus.

Schneider, Norbert F.; Limmer, Ruth; Ruckdeschel, Kerstin 2002b: Berufsmobilität und Lebensform. Sind berufliche Mobilitätserfordernisse in Zeiten der Globalisierung noch mit Familie vereinbar? Schriftenreihe des Bundesministeriums für Familie, Senioren, Frauen und Jugend. Stuttgart: Kohlhammer.

Schneider, Norbert F.; Meil, Gerado 2008 (Eds.): Mobile Living Across Europe. Volume I: Relevance and Diversity of Job-Related Spatial Mobility in six European Countries. Opladen/Farmington Hills: Barbara Budrich.

Schneider, Norbert F.; Ruppenthal, Silvia; Lück, Detlev; Rüger, Heiko; Dauber, Andrea 2008: Germany - A Country of Locally Attached but Highly Mobile People. In: Schneider, Norbert F.; Meil, Gerardo (Eds.): Mobile Living Across Europe I. Relevance and Diversity of Job-Related Spatial Mobility in Six European Countries. Opladen/Farmington Hills: Barbara Budrich Publishers: 105-147.

Schneider, Norbert F.; Collet, Beate 2010 (Eds.): Mobile Living Across Europe II. Opladen/Farmington Hills: Barbara Budrich Publishers.

Statistisches Bundesamt 2005: Leben und Arbeiten in Deutschland. Wiesbaden. 
Sternberg, Robert J. 1988: Triangulating love. In: Sternberg, Robert J.; Barnes, M.L. (Eds.): The Psychology of Love, New Haven. London: Yale University Press: 119-138.

Stevens, Daphne; Kiger, Gary; Riley, Pamela J. 2001: Working hard and hardly working: Domestic Labor and marital satisfaction among dual-earner couples. In: Journal of Marriage and Family 63,2: 514-526 [doi: 10.1111/j.1741-3737.2001.00514.x].

Stutzer, Alois; Frey, Bruno S. 2008: Stress that Doesn't Pay: The Commuting Paradox. In: Scand. Journal of Economics 110: 339-366 [doi: 10.1111/j.1467-9442.2008.00542.x.].

Viry, Gil; Widmer, Eric D.; Kaufmann, Vincent 2010: Does it matter for us that my partner or I commute? Spatial mobility for job reasons and the quality of conjugal relationships in France, Germany, and Switzerland. In: Zeitschrift für Familienforschung 22,2: 149-169.

Weiß, Bernd; Wagner, Michael 2008: Stehen Konflikte einer guten Partnerschaft entgegen? Eine empirische Analyse auf Grundlage dyadischer Daten. In: Feldhaus, Michael; Huinink, Johannes (Eds.): Neuere Entwicklungen in der Beziehungs- und Familienforschung. Vorstudien zum Beziehungs- und Entwicklungspanel (PAIRFAM). Würzburg: Ergon: 187-228.

Widmer, Eric D.; Giudici, Francesco; Le Goff, Jean-Marie; Pollien, Alexandre 2009: From Support to Control: A Configurational Perspective on Conjugal Quality. In: Journal of Marriage and Family 71: 437-448 [doi: 10.1111/j.1741-3737.2009.00611.x].

Widmer, Eric D.; Kellerhals, Jean; Levy, Rene 2006: What pluralization of familiy relations? Conflicts, conjugal interaction styles, and social milieu. In: Revue française de sociologie 47, Supplément: 131-156.

Wilkie, Jane R.; Ferree, Myra M.; Ratcliff, Katheryn 1998: Gender and Fairness: Marital Satisfaction in Two-Earner Couples. In: Journal of Marriage and the Family 60,3: 577-594.

A German translation of this reviewed and authors' authorised original article by the authors' is available under the title "Berufsbezogene zirkuläre Mobilität und Partnerschaftszufriedenheit", DOI 10.4232/10.CPoS-2013-07de or URN urn:nbn:de:bib-cpos-2013-07de2, at http://www.comparativepopulationstudies.de.

Dr. Michael Feldhaus $(\bowtie)$. Universität Bremen, Institut für empirische und angewandte Soziologie (EMPAS), Bremen, Germany. E-Mail: feldhaus@empas.uni-bremen.de URL: www.empas.uni-bremen.de

Dr. Monika Schlegel. University of Vechta, Institute for Social Work, Education and Sport Sciences, Vechta, Germany. E-Mail: monika.schlegel@uni-vechta.de

URL: www.uni-vechta.de 


\section{Comparative Population Studies - Zeitschrift für Bevölkerungswissenschaft}

wWw.comparativepopulationstudies.de

ISSN: 1869-8980 (Print) - 1869-8999 (Internet)

Published by / Herausgegeben von

Prof. Dr. Norbert F. Schneider

Federal Institute for Population Research

D-65180 Wiesbaden / Germany

Managing Editor /

Verantwortlicher Redakteur

Frank Swiaczny

Assistant Managing Editor /

Stellvertretende Redakteurin

Katrin Schiefer

Language \& Copy Editor (English) /

Lektorat \& Übersetzungen (englisch)

Amelie Franke

Copy Editor (German) /

Lektorat (deutsch)

Dr. Evelyn Grünheid

\section{Layout / Satz}

Beatriz Feiler-Fuchs

E-mail: cpos@bib.bund.de

\author{
Scientific Advisory Board / \\ Wissenschaftlicher Beirat \\ Jürgen Dorbritz (Wiesbaden) \\ Paul Gans (Mannheim) \\ Johannes Huinink (Bremen) \\ Marc Luy (Wien) \\ Clara H. Mulder (Groningen) \\ Notburga Ott (Bochum) \\ Peter Preisendörfer (Mainz)
}

\section{Board of Reviewers / Gutachterbeirat} Martin Abraham (Erlangen)

Laura Bernardi (Lausanne) Hansjörg Bucher (Bonn) Claudia Diehl (Göttingen) Andreas Diekmann (Zürich) Gabriele Doblhammer-Reiter (Rostock) Henriette Engelhardt-Wölfler (Bamberg) E.-Jürgen Flöthmann (Bielefeld) Alexia Fürnkranz-Prskawetz (Wien) Beat Fux (Zürich) Joshua Goldstein (Rostock) Karsten Hank (Köln) Sonja Haug (Regensburg) Franz-Josef Kemper (Berlin) † Michaela Kreyenfeld (Rostock) Aart C. Liefbroer (Den Haag) Kurt Lüscher (Konstanz) Dimiter Philipov (Wien) Tomáš Sobotka (Wien) Heike Trappe (Rostock) 